\title{
Crystal-Phase Control of Ternary Metal Oxides by Solid-State Synthesis with Nanocrystals
}

\author{
Anna Loiudice, Bastien P.G. Niau, Raffaella Buonsanti*
}

Laboratory of Nanochemistry for Energy Research, Institute of Chemical Sciences and Engineering, Ecole Politechnique Fédérale de Lausanne, Sion, CH-1950, Switzerland.

*Correspondence to: raffaella.buonsanti@epfl.ch
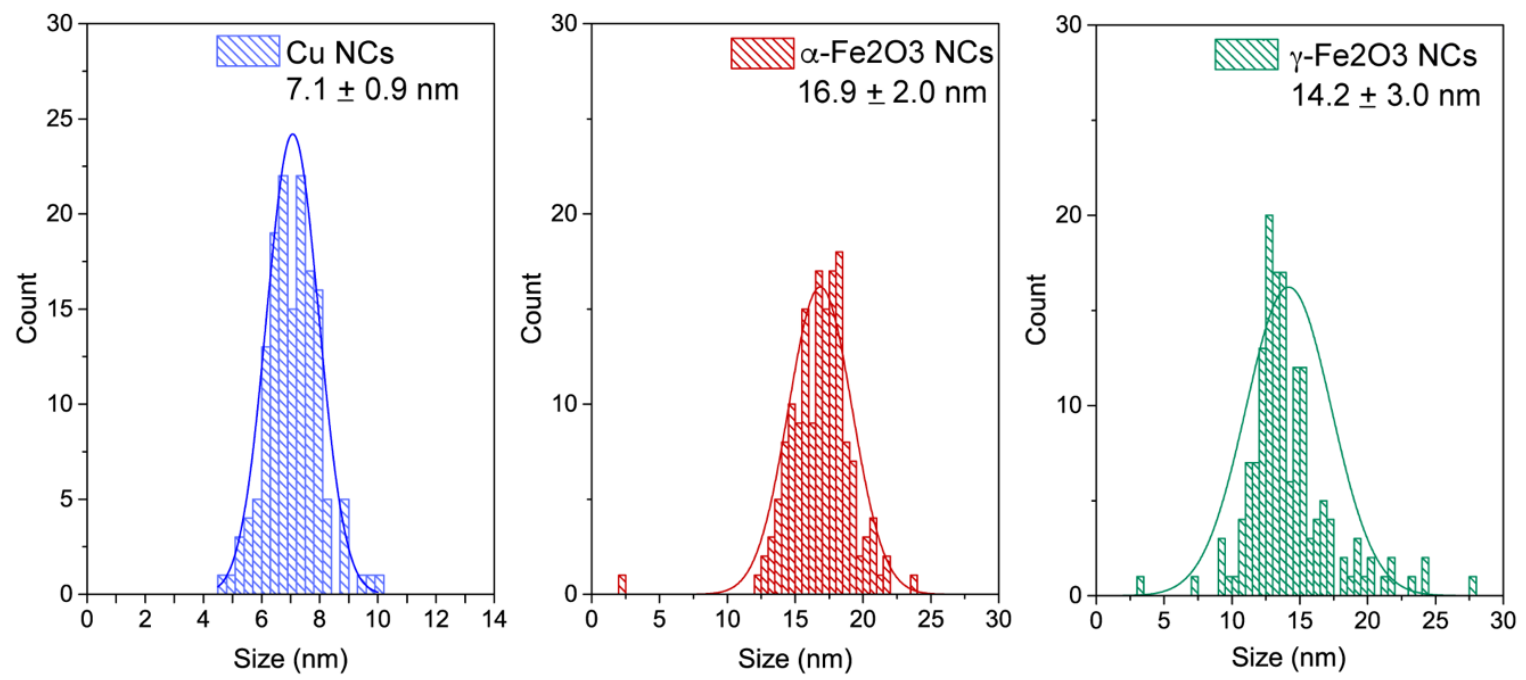

Figure S1. Histogram of the size distribution of the NC precursors used in this work. 

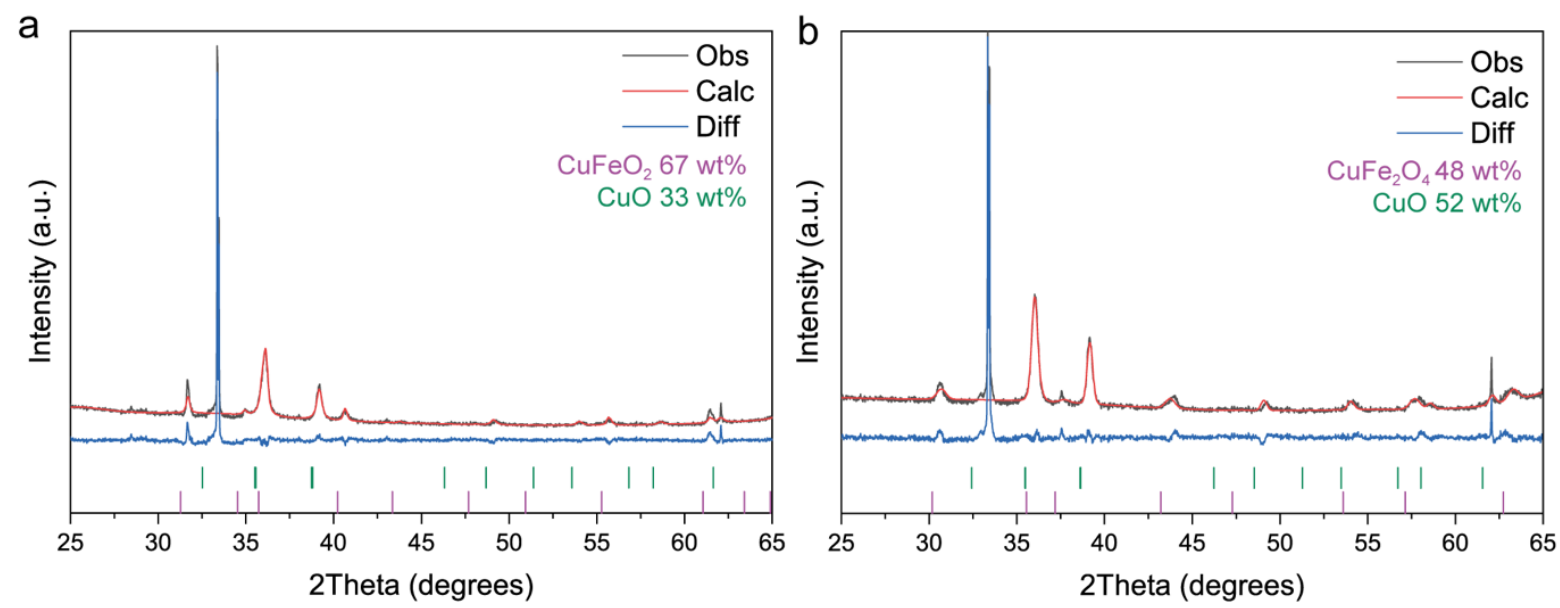

Figure S2. XRD Rietveld refinements for the products obtained by annealing a) the ( $\alpha$ $\left.\mathrm{Fe}_{2} \mathrm{O}_{3}+\mathrm{Cu}\right) \mathrm{NC}$ system and b) $\left(\gamma-\mathrm{Fe}_{2} \mathrm{O}_{3}+\mathrm{Cu}\right) \mathrm{NC}$ system.

Rietveld refinements were performed with Topas, refining for each phase the scale factor, size broadening (instrumental resolution determined empirically using SRM 1976c) and one thermal displacement parameter per atom type. Additional refinement parameters were the zero shift of the detector, the vertical displacement of the sample, and the coefficients of a Chebyshev polynomial describing the background. Figure S2 shows that for both systems $\mathrm{CuO}$ is present as second phase. Moreover, the estimated grain size for the annealed sample in a) is of $51 \pm 2 \mathrm{~nm}$ for the $\mathrm{CuFeO}_{2}$ phase and in b) of $14 \pm 3 \mathrm{~nm}$ for the $\mathrm{CuFe}_{2} \mathrm{O}_{4}$ phase in agreement with the TEM analysis after annealing. 

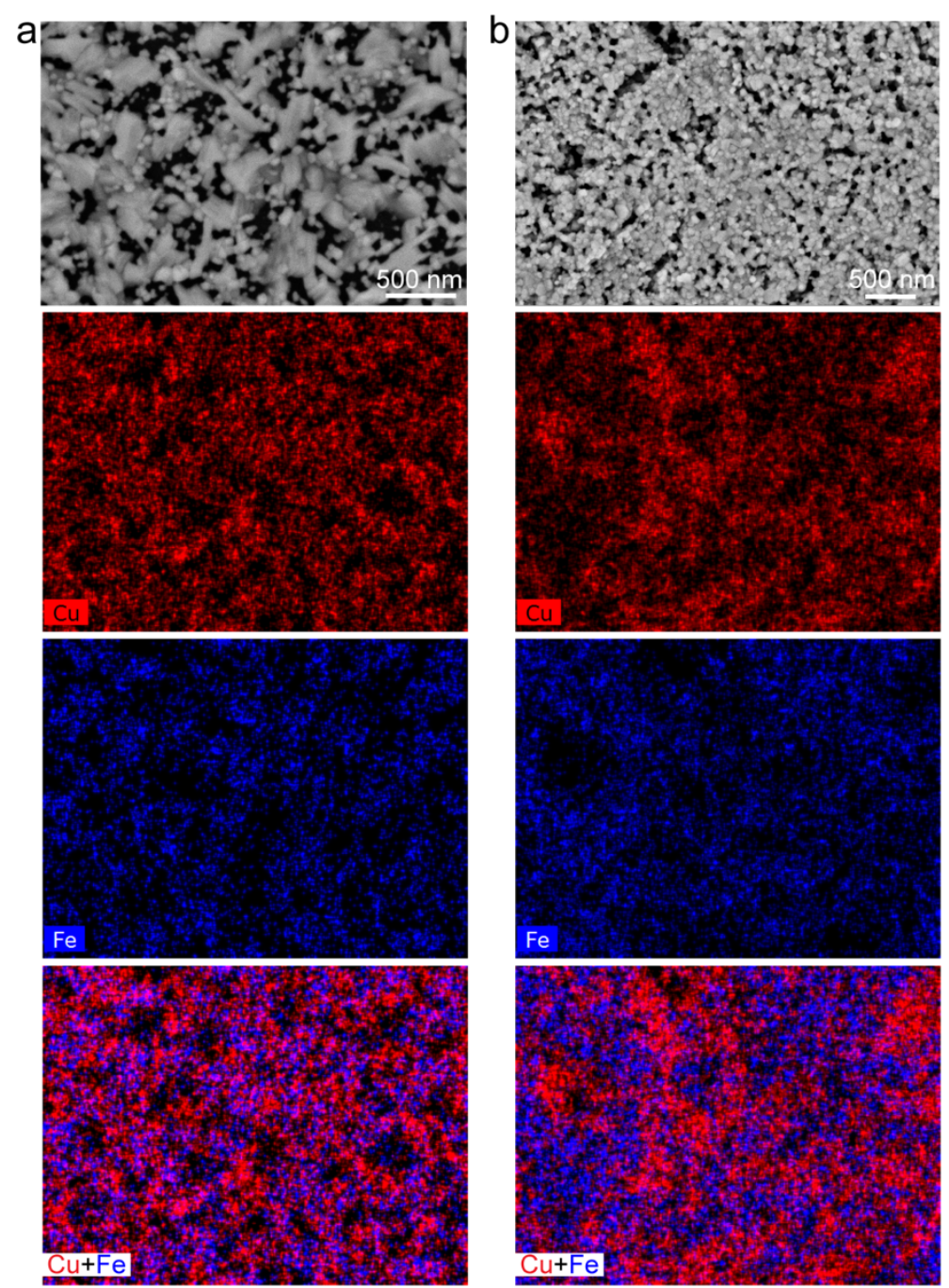

Figure S3. Planar SEM images together with the $\mathrm{Cu}, \mathrm{Fe}$ and $\mathrm{Cu}+\mathrm{Fe}$ EDXS maps for a) the film obtained after annealing $\alpha-\mathrm{Fe}_{2} \mathrm{O}_{3}+\mathrm{Cu} \mathrm{NCs}$ and $\mathrm{b}$ ) after annealing $\gamma-\mathrm{Fe}_{2} \mathrm{O}_{3}+\mathrm{Cu} \mathrm{NCs}$ both at $700^{\circ} \mathrm{C}$ for 30 min under $\mathrm{N}_{2}$ atmosphere. 

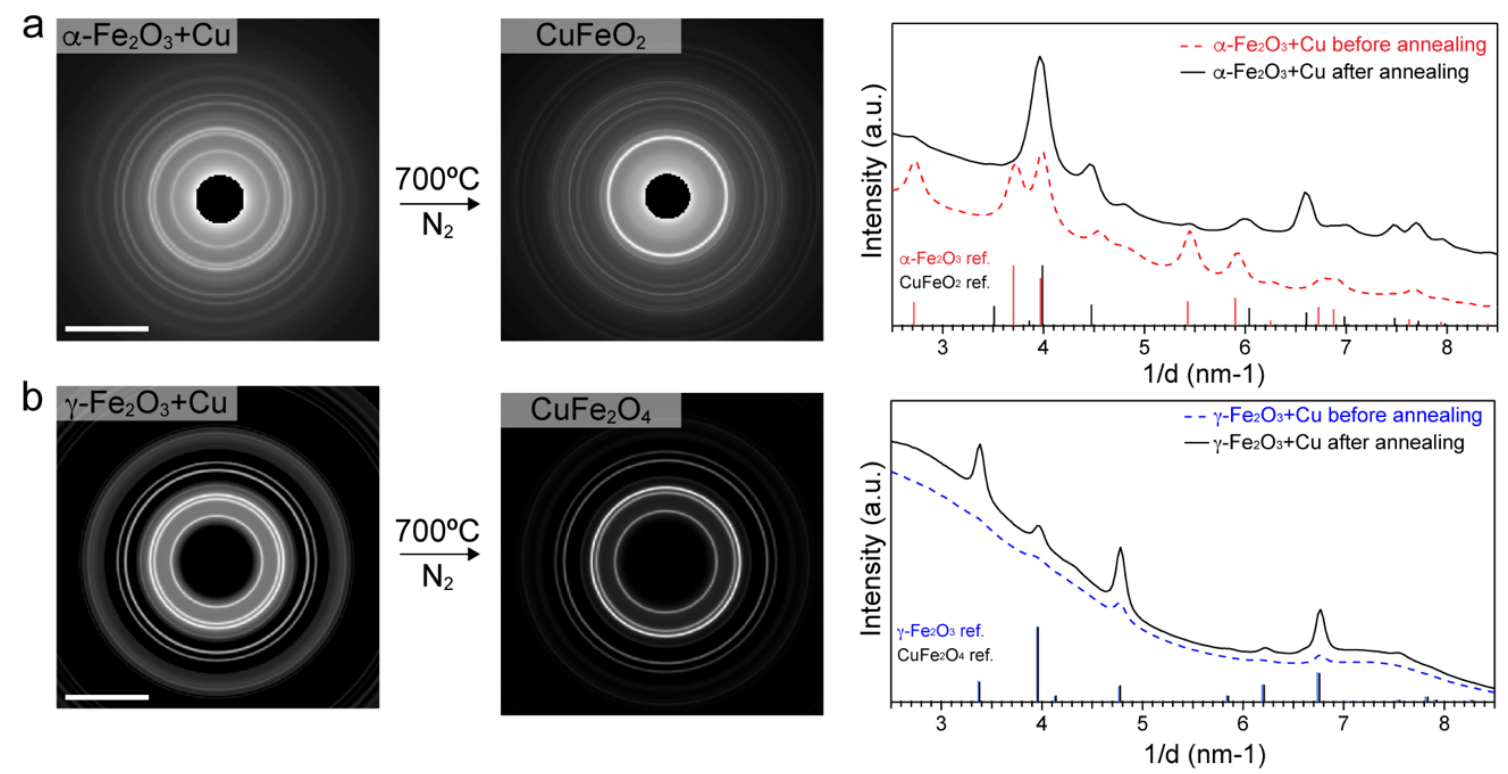

Figure S4. Identical location selected area electron diffraction images before and after annealing at $700^{\circ} \mathrm{C}$ for 30 min under $\mathrm{N}_{2}$ together with the corresponding integrated patterns a) for $\left(\alpha-\mathrm{Fe}_{2} \mathrm{O}_{3}+\mathrm{Cu}\right) \mathrm{NCs}$ and $\left.b\right)$ for $\left(\gamma-\mathrm{Fe}_{2} \mathrm{O}_{3}+\mathrm{Cu}\right) \mathrm{NCs}$. The scale bar corresponds to $5 \mathrm{~nm}^{-1}$. 
$\mathrm{Fe}_{\mathrm{A}}$ site $\bigcirc \mathrm{Fe}_{\mathrm{B}}$ site $\mathrm{Fe}_{\mathrm{B}}$ vacancy $\bigcirc \mathrm{O} \mathrm{Cu}$

a

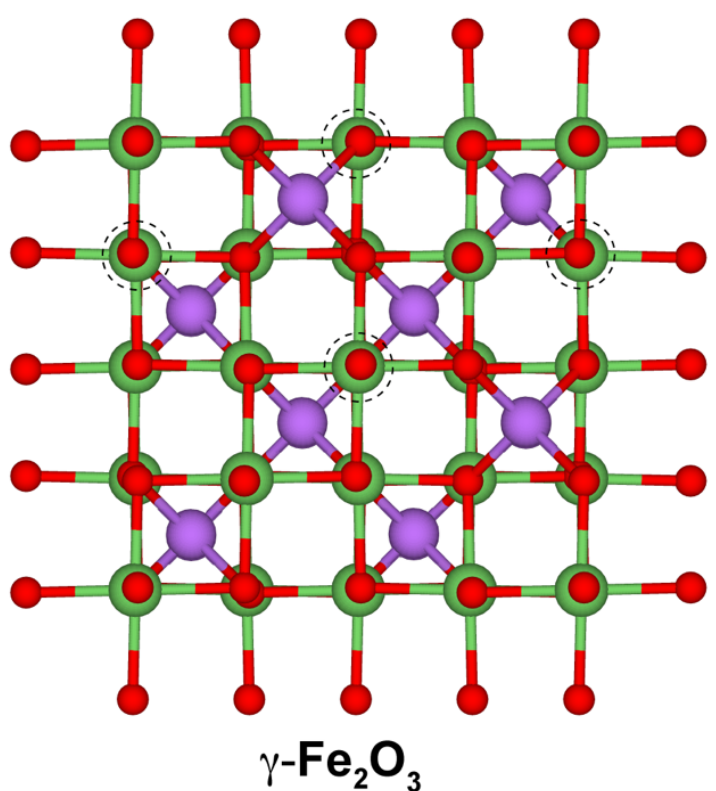

C

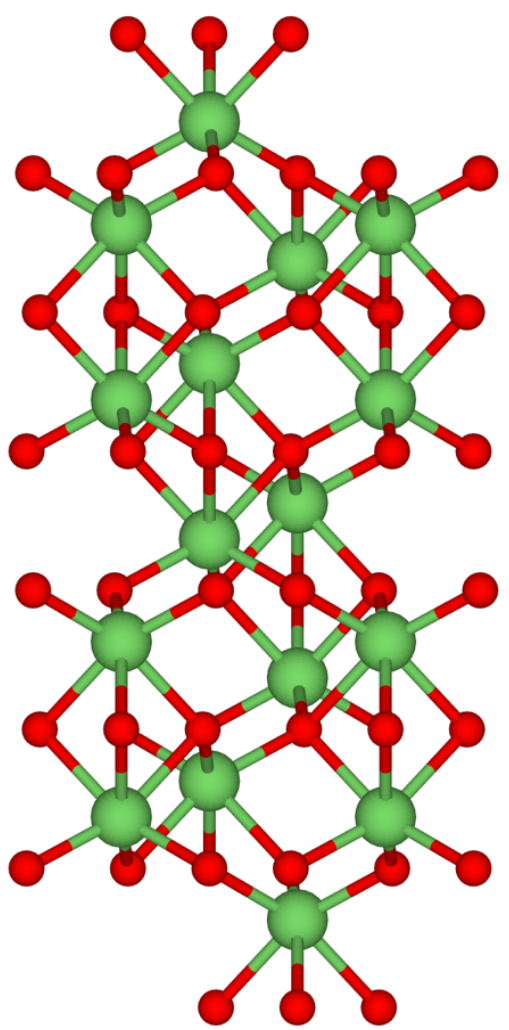

$\alpha-\mathrm{Fe}_{2} \mathrm{O}_{3}$ b

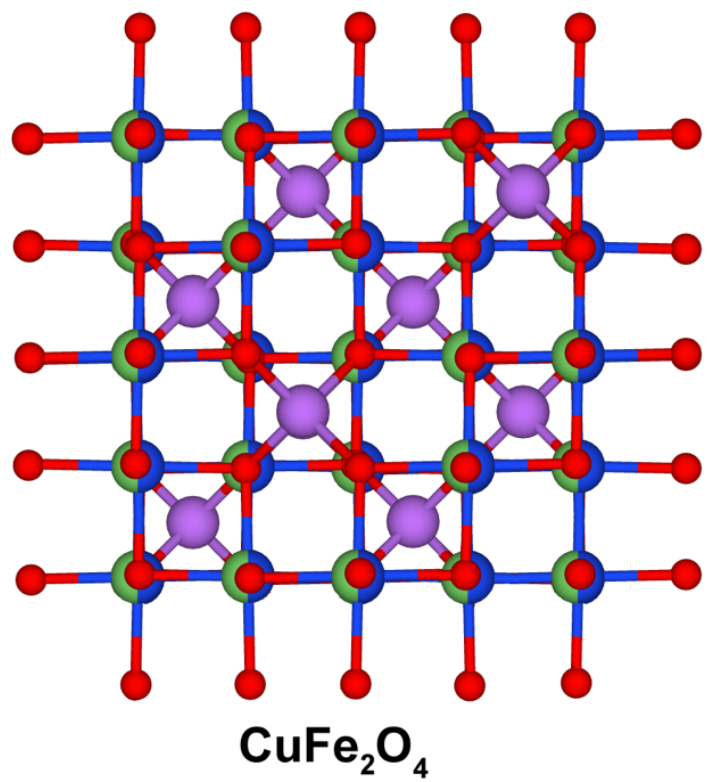

d

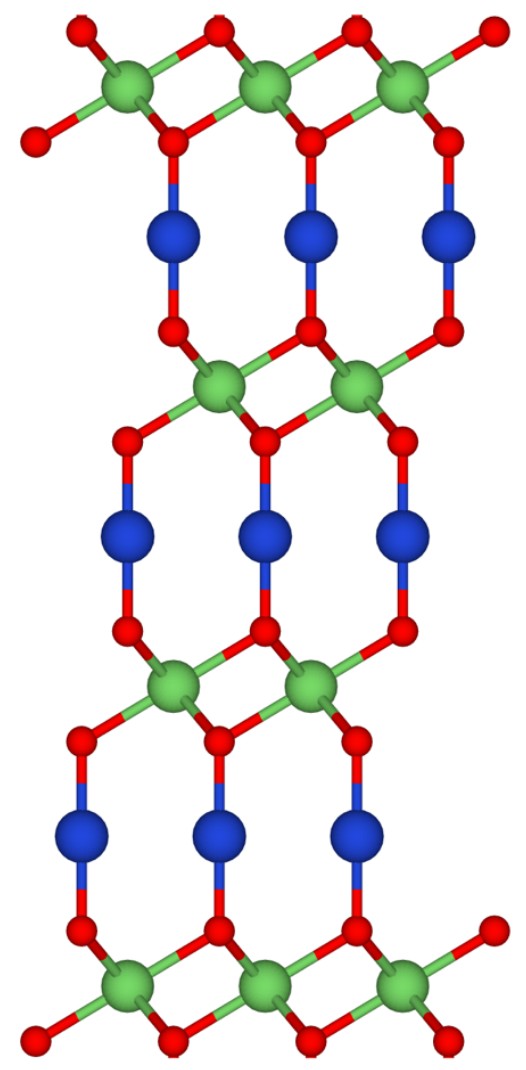

$\mathrm{CuFeO}_{2}$

Figure S5. Graphical representations of the crystal structures of a) $\gamma-\mathrm{Fe}_{2} \mathrm{O}_{3}$ and b) $\mathrm{CuFe} \mathrm{O}_{4}$ (view along b axis), c) $\alpha-\mathrm{Fe}_{2} \mathrm{O}_{3}$ and d) $\mathrm{CuFeO}_{2}$ (view along a axis). $\gamma-\mathrm{Fe}_{2} \mathrm{O}_{3}$ has a cubic crystal structure of an inverse spinel type characterized by $\mathrm{Fe}$ cations in two nonequivalent crystallographic sites, i.e., the tetrahedral $\mathrm{F}_{\mathrm{A}}$ (purple) and octahedral $\mathrm{F}_{\mathrm{B}}$ (green) sites. 
Additionally, its structure features vacant cation sites $F_{B}$ vacancy (indicated with dotted circles), which usually occur in octahedral positions, to compensate for the positive charge. These vacancies along with their similar crystalline structures favors the migration of copper ions and the transformation into the spinel $\mathrm{CuFe}_{2} \mathrm{O}_{4}$.
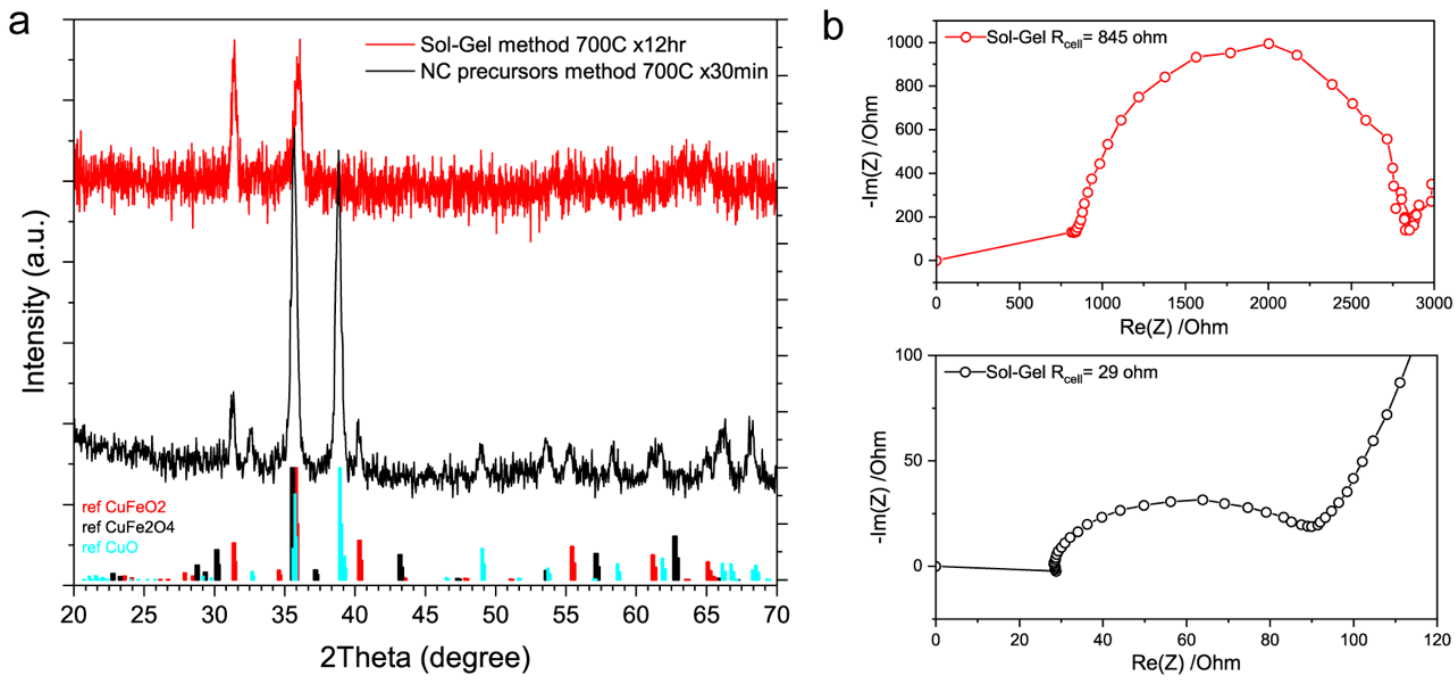

Figure S6. a) XRD spectra of $\mathrm{CuFeO}_{2}$ film obtained by sol-gel method (red line) and $\mathrm{NC}$ precursor reaction (black line); b) Electrochemical impedance spectra measured for the films in a) fabricated on FTO substrates. The obtained $R_{\text {cell }}$ for each film is reported on the graphs.

The sol-gel method was reproduced from a previous work. ${ }^{1}$ Electrochemical impedance spectroscopy was used to determine the electrochemical cell resistance $\left(\mathrm{R}_{\text {cell }}\right)$. $\mathrm{CO}_{2}$ saturated $0.1 \mathrm{M} \mathrm{KHCO}_{3}$ was used as electrolyte. The spectra were measured at the open-circuit potential, using 41 points between $1 \mathrm{MHz}$ and $100 \mathrm{~Hz}$, a sinus amplitude of $20 \mathrm{mV}$ and a pause time of $0.6 \mathrm{~s}$ between each frequency. The $\mathrm{R}_{\text {cell }}$ value was extracted from the Nyquist plot taking the value of $\operatorname{Re}(Z)$ at the minimum value of $-\operatorname{Im}(Z)$ before the charge- transfer arc. Being the cell, the electrolyte, the substrate equal for both samples, these results demonstrate that the films prepared from the nanocrystal precursors possess a lower electrical resistance than those prepared from molecular precursor via sol-gel chemistry, which is promising for future application as photoelectrodes.

\section{Reference}

1. Prõvot, M. S.; Guijarro, N.; Sivula, K. Enhancing the Performance of a Robust Sol-GelProcessed p-Type Delafossite $\mathrm{CuFeO} 2$ Photocathode for Solar Water Reduction. ChemSusChem 2015, 8, 1359 - 1367. 